\author{
Rita Laura Segato
}

Universidade de Brasília

\title{
Território, soberania e crimes de segundo Estado: a escritura nos corpos das mulheres de Ciudad Juarez
}

\begin{abstract}
Resumo: O ensaio examina o caso dos feminicídios que resultaram em pelo menos 300 mulheres assassinadas durante os últimos 11 anos em Ciudad Juarez, Chihuahua, na fronteira norte do México. Em todos esses anos, as autoridades apresentaram somente uns poucos suspeitos, sem nunca conseguir convencer a opinião pública de sua culpabilidade. Impunidade e proteção dos assassinos são evidentes tanto para a opinião pública local como para os observadores internacionais. Eu sugiro que o que é escrito no corpo das mulheres brutalmente assassinadas é a assinatura de um poder local e regional que também conta com tentáculos nacionais. Esses atos de violência aparentemente irracional enunciam, para além de qualquer dúvida, o poder discricionário de seus perpetradores e o controle que eles detêm sobre pessoas e recursos de seu território, selando e reforçando com isso um pacto de fraternidade.
\end{abstract}

Palavras-chave: violência expressiva, violência de gênero, máfias, masculinidade, territorialidade, poder econômico.

Copyright (๑) 2005 by Revista Estudos Feministas

' Este artigo já foi publicado em espanhol no livro Ciudad Juárez: de este lado del puente (México: Epikeia e Instituto Nacional de las Mujeres, nov. 2004) e na revista virtual labrys, estudos feministas, études féministes (n. 6, ago./dez. 2004-août/déc. 2004, disponível em http://www.unb.br/ih/his/ gefem/labrys6/pl.htm).
Ciudad Juárez, estado de Chihuahua, fronteira norte do México com El Paso, Texas, é um lugar emblemático do sofrimento das mulheres. Ali, mais do que em qualquer outro lugar, torna-se real o lema "corpo de mulher, perigo de morte". Ciudad Juárez é também, significativamente, um lugar emblemático da globalização econômica e do neoliberalismo, com sua fome insaciável de ganância. A sombra sinistra que cobre a cidade e o medo constante que senti durante cada dia e cada noite da semana em que ali estive me acompanham até hoje, mais de um mês depois de meu regresso ao Brasil. Ali se mostra a relação direta que existe entre capital e morte, entre acumulação e concentração desreguladas e o sacrifício de mulheres pobres, escuras, mestiças, devoradas pela fenda onde se 
articulam economia monetária e economia simbólica, controle de recursos e poder de morte.

Fui convidada para ir a Ciudad Juárez durante o mês de julho de 2004 porque, no ano anterior, duas mulheres das organizações mexicanas Epikeia e Nuestras Hijas de Regreso a Casa haviam-me escutado formular o que me pareceu ser a única hipótese viável para os enigmáticos crimes que assolavam a cidade - as mortes de mulheres de tipo físico semelhante que, sendo desproporcionalmente numerosas e contínuas ao longo de agora 11 anos, perpetradas com excesso de crueldade, com evidência de estupros coletivos e torturas, apresentavam-se como ininteligíveis.

O compromisso inicial de nove dias para participar de um fórum sobre os feminicídios de Juárez foi interrompido por uma série de acontecimentos que culminaram, no sexto dia, com a queda do sinal de televisão a cabo na cidade inteira quando comecei a expor minha interpretação dos crimes em uma entrevista com o jornalista Jaime Pérez Mendoza, do canal 5 local. A assustadora precisão cronométrica com que coincidiram a queda do sinal e a primeira palavra com a qual iria dar início à minha resposta sobre o porquê dos crimes fez com que decidíssemos partir, deixando Ciudad Juárez na manhã seguinte, para nos preservarmos e como protesto pela censura sofrida. Qual não seria nossa impressão ao perceber que todos aqueles com os quais falamos confirmaram-nos que a decisão de ir embora de imediato era sensata.

Não esquecíamos que em Ciudad Juárez não parece haver coincidências fortuitas e, tal como tentarei argumentar, tudo parece fazer parte de uma grande máquina comunicativa cujas mensagens tornam-se inteligíveis somente para quem, por alguma razão ou outra, adentrou o código. É por isso que o primeiro problema que os horrendos crimes de Ciudad Juárez apresentam ao forasteiro, às audiências distantes, é um problema de inteligibilidade. E é justamente em sua ininteligibilidade que os assassinos refugiam-se, como em um tenebroso código de guerra, um argot composto inteiramente de acting outs. Somente para dar um exemplo dessa lógica da significação, a jornalista Graciela Atencio, do jornal La Jornada da Cidade do México, também se perguntou, em uma de suas matérias sobre as mulheres assassinadas em Ciudad Juárez, se teria sido algo a mais do que coincidência que justamente no dia 16 de agosto de 2003, quando seu jornal publicava pela primeira vez a notícia de um revelador "informe do $\mathrm{FBI}$ que descrevia um possível modus operandi no seqüestro e desaparecimento de jovens", problemas de

${ }^{2}$ ATENCIO, 2003 correio impediram sua distribuição em Ciudad Juárez. ${ }^{2}$ 
3 Os restos de Alma Brisa foram encontrados entre girassóis no mesmo terreno do centro da cidade onde havia sido encontrado o corpo de Brenda Berenice, filha de Juanita, uma das principais colaboradoras do projeto de Epikeia e personagem do livro de entrevistas onde este texto apareceu publicado pela primeira vez (Ciudad Juárez: de este lado del puente).
Desafortunadamente, não tinha sido essa a única coincidência que nos pareceu significativa durante nossa estada na cidade. Na segunda-feira, dia 26 de julho, depois de ter terminado minha primeira exposição, a meio caminho da duração total do fórum que nos reunia e exatamente quatro meses depois de terem encontrado o último corpo, apareceu o cadáver de uma trabalhadora de maquiladora, Alma Brisa Molina Baca. Poupo aqui o relato da quantidade de irregularidades cometidas pelos investigadores e pela imprensa local em relação aos restos de Alma Brisa. Era, sem qualquer exagero, ver-para-crer; estar ali para ser testemunha do inconcebível, do inacreditável. Porém, faço notar, sim, que o corpo apareceu no mesmo terreno baldio do centro da cidade onde, no ano anterior, outra vítima fora encontrada. Esta outra vítima era a filha assassinada - ainda criança - da mãe que precisamente tínhamos entrevistado na véspera, dia 25 de julho, no sombrio bairro Lomas de Poleo, situado no deserto inclemente que atravessa a fronteira entre Chihuahua e o estado do Novo México, no país vizinho. ${ }^{3}$ Os comentários gerais também apontavam para o fato de que, no ano passado, justamente coincidindo com a intervenção federal no estado de Chihuahua, ordenada pelo presidente Fox, outro corpo havia sido encontrado. As cartas estavam dadas. O sinistro "diálogo" parecia confirmar que estávamos dentro do código e que o rastro que seguíamos conduzia a um desfecho.

Esse é o caminho interpretativo que desejo expor aqui e, também, aquilo que estava por começar a dizer quando o sinal de televisão a cabo caiu, na madrugada de sextafeira, dia 30 de julho de 2004. Trata-se, justamente, da relação entre as mortes, os ilícitos resultantes do neoliberalismo feroz que se globalizou nas margens da Grande Fronteira depois do NAFTA e a acumulação desregulada que se concentrou nas mãos de algumas famílias de Ciudad Juárez. De fato, o que mais impressiona quando se ausculta Ciudad Juarez é a veemência com que a opinião pública rejeita um a um os nomes que as forças públicas apresentam como supostos culpáveis. Dá impressão de que as pessoas, apesar de desnorteadas, desejam olhar para outra direção, esperam que a polícia dirija suas suspeitas para o outro lado, em direção aos bairros ricos da cidade.

O tráfico ilegal de todo tipo de lucro para o outro lado inclui as mercadorias produzidas pelo trabalho extorquido das trabalhadoras das maquiladoras, o valor excedente que a mais-valia extraída desse trabalho agrega, além de drogas, corpos e, por fim, a soma dos consideráveis capitais que esses negócios geram ao sul do paraíso. Seu trânsito ilícito assemelha-se a um processo de devolução 
constante a um tributador injusto, voraz e insaciável que, no entanto, esconde sua demanda e desincumbe-se da sedução que exerce. A fronteira entre a miséria-do-excesso e a miséria-da-falta é um abismo.

Existem duas coisas que em Ciudad Juarez podem ser ditas sem risco, e que, ademais, todo o mundo diz - a polícia, a Procuradoria Geral da Republica, a Procuradora Especial, o Comissionado dos Direitos Humanos, a imprensa e as ativistas das ONGs: uma delas é que "a responsabilidade pelos crimes é dos narcos", remetendonos a um sujeito com aspecto de malfeitor e reafirmando nosso terror quanto às margens da vida social. A outra é que "se trata de crimes de motivo sexual". O jornal de terçafeira, um dia depois de terem encontrado o corpo de Alma Brisa, repetia: "mais um crime de motivo sexual", e a fiscalização especial ressaltava: "é muito difícil conseguir reduzir os crimes sexuais", confundindo uma vez mais as evidências e desorientando o público ao conduzir seu raciocínio por um caminho que creio que é equivocado.

É dessa forma que autoridades e formadores de opinião, ainda que pretendam falar em nome da lei e dos direitos, estimulam uma percepção indiscriminada da quantidade de crimes misóginos que ocorrem nessa localidade, como em qualquer outra do México, da América Central e do mundo: crimes passionais, violência doméstica, abuso sexual, estupro por mãos de agressores seriais, crimes por dívidas de tráfico, tráfico de mulheres, crimes de pornografia virtual, tráfico de órgãos etc. Entendo essa vontade de indistinção, assim como também a permissividade e naturalidade com que em Ciudad Juárez se percebem todos os crimes contra as mulheres, como um smoke-screen, uma cortina de fumaça cuja conseqüência é impedir que se veja claro um núcleo central que apresenta características particulares e semelhantes.

É como se círculos concêntricos formados por uma variedade de agressões ocultassem em seu interior um tipo de crime particular, não necessariamente o mais numeroso, mas sim o mais enigmático por suas características precisas, quase burocráticas: seqüestro de mulheres jovens com um tipo físico definido e em sua maioria trabalhadoras ou estudantes, privação da liberdade por alguns dias, torturas, estupros "coletivos" - como declarou no fórum o ex-chefe de perícia Oscar Máynez mais de uma vez -, mutilação, estrangulamento, morte certa, mistura ou extravio de pistas e evidências por parte das forças da lei, ameaças e atentados contra advogados e jornalistas, pressão 
4 The Harvest of Women, de aparição próxima no México e nos Estados Unidos da América do Norte, fragmentos do qual foram aparecendo em sua coluna do jornal El Paso Times.

${ }^{5}$ GONZÁLEZ RODRÍGUEZ, 2002. deliberada das autoridades para culpar bodes expiatórios claramente inocentes, e continuidade ininterrupta dos crimes desde 1993 até hoje. A essa lista soma-se o fato de que nunca nenhum acusado pareceu verossímil para a comunidade e nenhuma "linha de investigação" demonstrou resultados.

A impunidade, ao longo de agora 11 anos, revelase espantosa, e pode ser descrita em três aspectos: 1) ausência de acusados convincentes para a opinião pública; 2) ausência de linhas de investigação consistentes; e 3) a conseqüência das duas anteriores: o círculo de repetição sem fim desse tipo de crime.

Por outro lado, dois corajosos jornalistas de investigação, Diana Washington - que está preparando um livro sobre as mulheres assassinadas em Ciudad Juáre $z^{4}-e$ Sergio González Rodríguez - autor de Huesos em el desierto, ${ }^{5}$ golpeado e dado por morto em uma rua da Cidade do México há quatro anos, quando se encontrava em plena investigação para seu livro, o que lhe causou a perda de todos os dentes e obrigou-o a permanecer um mês hospitalizado - juntaram numerosos dados que a polícia descartou ao longo dos anos e chegaram a uma lista de lugares e pessoas que têm, de uma forma ou outra, relação com os desaparecimentos e assassinatos das mulheres.

Conversei com Diana Washington em duas oportunidades do outro lado da fronteira (pois o FBI não permite cruzar a ponte sem escolta) e li o livro de Sergio González. O que se mostra é que pessoas "de bem", grandes proprietários, estão vinculados com as mortes. Falta, no entanto, um elo crucial: o que leva esses respeitados chefes de família, exitosos nas finanças, a se envolver em crimes macabros e, pelo que tudo indica, cometidos coletivamente? Qual será o vínculo plausível entre esses senhores e os seqüestros e estupros coletivos que permitiria indiciá-los e levá-los a julgamento? Falta aí uma razão. E é justamente aqui, na procura por essa razão, que a idéia da qual tanto se abusa do "motivo sexual" resulta insuficiente.

Novas tipificações e um refinamento das definições fazem-se necessários para que seja possível compreender a especificidade de um número restrito das mortes de Juárez, e é necessário formular novas categorias jurídicas. Especialmente, é necessário dizer o que parece óbvio: que nenhum crime realizado por marginais comuns prolongase por tanto tempo em total impunidade, e que nenhuma polícia séria fala com tamanha leviandade sobre o que, em geral, é um produto de uma longa investigação: o motivo, o impulso, a razão de um crime. Essas verdades elementares causaram estremecimento em Ciudad Juárez e resultaram impronunciáveis. 
${ }^{6}$ Apresentei os resultados em meu livro Las estructuras elementales de la violencia. Ensayos sobre género entre la antropología, el psicoanálisis y los derechos humanos (SEGATO, 2003).

${ }^{7}$ AMIR, 1971.

\section{A clência e a vida}

Algum tempo antes de ter escutado falar de Ciudad Juárez pela primeira vez, entre os anos 1993 e 1995, conduzi uma pesquisa sobre a mentalidade dos condenados por estupro presos na penitenciária de Brasília. ${ }^{6}$ Minha "escuta" dos relatos desses presidiários, todos eles condenados por ataques sexuais realizados no anonimato das ruas e com vítimas desconhecidas, respalda a tese feminista fundamental de que os crimes sexuais não são obra de desvios individuais, doentes mentais ou anomalias sociais, mas sim expressões de uma estrutura simbólica profunda que organiza nossos atos e nossas fantasias e confere-lhes inteligibilidade.

Emerge das entrevistas com mais força do que nunca o que Menacher Amin já tinha descoberto em dados empíricos e na sua análise quantitativa: ${ }^{7}$ que, contrariando nossas expectativas, os estupradores, na maioria das vezes, não agem sozinhos, não são animais associais que espreitam suas vítimas como caçadores solitários, mas sim que o fazem em companhia. Não há palavras suficientes para enfatizar a importância dessa descoberta e suas conseqüências para entender os estupros como verdadeiros atos que acontecem in societate, quer dizer, em um nicho de comunicação que pode ser penetrado e entendido.

Uso e abuso do corpo do outro sem que este participe com intenção ou vontade compatíveis, o estupro dirige-se ao aniquilamento da vontade da vítima, cuja redução é justamente significada pela perda do controle sobre o comportamento de seu corpo e o agenciamento do mesmo pela vontade do agressor. A vítima é expropriada do controle sobre seu espaço-corpo. É por isso que se poderia dizer que o estupro é o ato alegórico por excelência da definição schmittiana de soberania - controle legislador sobre um território e sobre o corpo do outro como anexo a esse território. Controle irrestrito, vontade soberana arbitrária e discricionária cuja condição de possibilidade é o aniquilamento de atribuições equivalentes nos outros e, sobretudo, a erradicação da potência destes como índices de alteridade ou subjetividade alternativa. Nesse sentido, também esse ato está vinculado ao consumo do outro, a um canibalismo mediante o qual o outro perece como vontade autônoma, e sua oportunidade de existir somente persiste se é apropriada e incluída no corpo de quem o devorou. O resto de sua existência persiste somente como parte do projeto do dominador.

Por que o estupro adquire esse significado? Porque, devido à função da sexualidade no mundo que conhecemos, ele conjuga em um único ato a dominação 
física e moral do outro. E não existe poder soberano que seja somente físico. Sem a subordinação psicológica e moral do outro, o único que existe é poder de morte, e o poder de morte, por si só, não é soberania. A soberania completa é, em sua fase extrema, a de "fazer viver ou deixar morrer". 8 Sem domínio da vida enquanto vida, a dominação não pode completar-se. É por isso que uma guerra que resulta em extermínio não constitui vitória, porque somente o poder de colonização permite a exibição do poder de morte diante daqueles destinados a permanecer vivos. $O$ traço por excelência da soberania não é o poder de morte sobre o subjugado, mas sim sua derrota psicológica e moral, e sua transformação em audiência receptora da exibição do poder de morte discricionário do dominador.

É por sua qualidade de violência expressiva mais que instrumental - violência cuja finalidade é a expressão do controle absoluto de uma vontade sobre a outra - que a agressão mais próxima do estupro é a tortura, física ou moral. Expressar que se tem nas mãos a vontade do outro é o telos ou finalidade da violência expressiva. Domínio, soberania e controle são seu universo de significação. Cabe relembrar que estas últimas, no entanto, são capacidades que só podem ser exercidas diante de uma comunidade de vivos e, portanto, têm mais afinidade com a idéia de colonização que com a idéia de extermínio. Em um regime de soberania, alguns estão destinados à morte, para que em seu corpo o poder soberano grave sua marca; nesse sentido, a morte desses escolhidos para representar o drama da dominação é uma morte expressiva, não uma morte utilitária.

É necessário, entretanto, entender que toda violência, inclusive aquela em que domina a função instrumental, como, por exemplo, a que tem por objetivo apropriar-se do alheio, inclui uma dimensão expressiva, e nesse sentido pode-se dizer o que qualquer detetive sabe: que todo ato de violência, sendo um gesto discursivo, possui uma assinatura. E é nessa assinatura que se conhece a presença reiterada de um sujeito por detrás de um ato. Qualquer detetive sabe que, se reconhecemos o que se repete em uma série de crimes, poderemos identificar a assinatura - o perfil, a presença de um sujeito reconhecível por detrás do ato. O modos operandi de um agressor é nada mais nada menos do que a marca de um estilo em diversas alocuções. Identificar o estilo de um ato violento, como se identifica o estilo de um texto, leva-nos ao perpetrador, em seu papel de autor. Nesse sentido, a assinatura não é uma conseqüência da deliberação, da vontade, mas sim uma conseqüência do próprio automatismo da enunciação: o rastro reconhecível de um sujeito, de sua posição e de seus interesses, no que diz, no que expressa, em palavra, o ato. ${ }^{9}$ 
${ }^{10}$ Ver o capítulo "La célula violenta que Lacan no vio: un diálogo (tenso) entre la antropología y el psicoanálisis" em meu livro de 2003 já citado.
Se o estupro é, como afirmo, um enunciado, dirigese necessariamente a um ou vários interlocutores que se encontram fisicamente na cena ou presentes na paisagem mental do sujeito da enunciação. Acontece que o estuprador emite suas mensagens ao longo de dois eixos de interlocução e não somente de um, como geralmente se considera, quando se pensa exclusivamente em sua interação com a vítima.

No eixo vertical, ele fala, sim, à vítima, e seu discurso adquire um aspecto punitivo e o agressor, um perfil de moralizador, de campeão da moral social porque, nesse imaginário compartido, o destino da mulher é ser contida, censurada, disciplinada, reduzida, pelo gesto violento de quem reencarna, por meio desse ato, a função soberana.

Porém, é possivelmente o descobrimento de um eixo horizontal de interlocução o aporte mais interessante de minha investigação entre os presidiários de Brasília. Aqui, o agressor dirige-se a seus pares, e o faz de várias formas: solicita-lhes ingresso em sua sociedade e, a partir dessa perspectiva, a mulher estuprada comporta-se como uma vítima sacrificial imolada em um ritual iniciático; compete entre eles, mostrando que merece, por sua agressividade e poder de morte, ocupar um lugar na irmandade viril e até mesmo adquirir uma posição destacada em uma fratria que somente reconhece uma linguagem hierárquica e uma organização piramidal.

Isso é assim porque no longuíssimo tempo da história do gênero, tão longo que se confunde com a história da espécie, a produção da masculinidade obedece a processos diferentes aos da produção da feminilidade. Evidências em uma perspectiva transcultural indicam que a masculinidade é um status condicionado a sua obtenção - que deve ser reconfirmado com uma certa regularidade ao longo da vida - mediante um processo de prova ou conquista e, sobretudo, sujeito à exação de tributos de um outro que, por sua posição naturalizada nessa ordem de status, é percebido como o provedor do repertório de gestos que alimentam a virilidade. Este outro, no mesmo ato em que faz a entrega do tributo instaurador, produz sua própria exclusão da casta que consagra. Em outras palavras, para que um sujeito adquira seu status masculino, como um título, como um grau, é necessário que outro sujeito não o tenha, porém o outorgue ao longo de um processo persuasivo ou impositivo que possa ser eficientemente descrito como tributação. ${ }^{10} \mathrm{Em}$ condições sócio-politicamente "normais" na ordem de status, nós, as mulheres, somos as entregadoras do tributo; eles, os receptores e beneficiários. E a estrutura que os relaciona estabelece uma ordem simbólica marcada pela desigualdade que se encontra presente e organiza 
11 Como se afirma, por exemplo, no livro de Jill Radford e Diana E.H. Russell Femicide: The Politics of Woman Killing (RADFORD e RUSSELL, 1992). todas as outras cenas da vida social regidas pela assimetria de uma lei de status.

Em síntese, de acordo com esse modelo, o crime de estupro resulta de um mandato que emana da estrutura de gênero e garante, em determinados casos, o tributo que assegura o acesso de cada novo membro à confraria viril. E chego a pensar que o cruzamento tenso entre suas duas coordenadas, a vertical, de consumo da vítima, e a horizontal, condicionada à obtenção do tributo, é capaz de iluminar aspectos fundamentais do longo e estabelecido ciclo dos feminicídios de Ciudad Juárez. De fato, o que me levou a Ciudad Juárez é que meu modelo interpretativo do estupro é capaz de lançar uma nova luz sobre o enigma dos feminicídios e permite organizar as peças do quebracabeça, fazendo emergir um desenho reconhecível.

Inspirada nesse modelo que leva em conta e enfatiza o papel da coordenada horizontal de interlocução entre membros da fratria, tendo a não entender os feminicídios de Ciudad Juárez como crimes nos quais o ódio em relação às vítimas é o fator predominante. ${ }^{11}$ Não discuto que a misoginia, no sentido estrito de desprezo pela mulher, seja generalizada no ambiente onde os crimes ocorrem. Porém, estou convencida de que a vítima é o produto secundário do processo, uma peça descartável, e de que condicionamentos e exigências extremas para atravessar o umbral de pertencimento ao grupo de pares encontramse por detrás do enigma de Ciudad Juárez. Quem domina a cena são os outros homens e não a vítima, cujo papel é ser consumida para satisfazer a demanda do grupo de pares. Os interlocutores privilegiados nessa cena são os iguais, sejam estes aliados, sejam competidores: os membros da fratria mafiosa, para garantir o pertencimento e celebrar seu pacto; os antagonistas, para exibir poder diante dos competidores nos negócios; as autoridades locais, as autoridades federais, os ativistas, os acadêmicos e jornalistas que ousem intrometer-se no sagrado domínio, os parentes subalternos - pais, irmãos, amigos - das vítimas. Essas exigências e formas de exibicionismo são características do regime patriarcal de uma ordem mafiosa.

\section{Os feminicídios de Cludad Juárez: uma aposta criminológica}

Apresento aqui uma lista com algumas idéias que, combinadas, constelam-se em uma imagem possível do lugar, as motivações, as finalidades, os significados, as ocasiões e as condições de possibilidade dos feminicídios.

Meu problema aqui é que a exposição não pode mais ser feita em forma de lista, já que os temas expostos 
formam uma esfera de sentido; não uma sucessão linear de itens sucessivos, mas sim uma unidade significativa: o mundo de Ciudad Juárez. E é por isso que não é preciso que os feitos formem parte de uma consciência discursiva por parte dos autores, já que são, fundamentalmente, ações constitutivas de seu mundo. Falar de causas e efeitos não me parece adequado. Falar de um universo de sentidos entrelaçados e motivações inteligíveis, sim.

\section{O lugar - a Grande Fronteira}

Fronteira entre o excesso e a falta, Norte e Sul, Marte e a Terra, Ciudad Juárez não é um lugar alegre. Abriga muitos prantos, muitos terrores.

Fronteira que o dinheiro deve atravessar para alcançar a terra firme onde o capital encontra-se, finalmente, a salvo e dá seus frutos em prestígio, segurança, conforto e saúde. A fronteira detrás da qual o capital moraliza-se e encontram-se os bancos que valem a pena.

A fronteira com o país mais controlado do mundo, com seus rastreamentos de vigilância cerrada e quase infalível. A partir desse ponto, dessa linha no deserto, qualquer negócio ilícito deve ser executado com um sigilo mais estrito, em sociedades clandestinas mais coesas e juradas que em qualquer outro lugar. O lacre de um silêncio rigoroso é seu requisito.

A fronteira onde os grandes empresários vivem de um lado e "trabalham" do outro; da grande expansão e valorização territorial - literalmente, terrenos roubados do deserto cada dia, cada vez mais próximo do Rio Bravo.

A fronteira do tráfico mais lucrativo do mundo: tráfico de drogas, tráfico de corpos.

A fronteira que separa uma das mãos-de-obra mais caras do mundo de uma das mãos-de-obra mais baratas.

Essa fronteira é o cenário do maior e mais prolongado número de ataques e assassinatos de mulheres com modus operandi semelhante de que se tem notícia em "tempos de paz".

\section{Os propósitos}

A evidência de um longuíssimo período de inércia da Justiça em torno dos crimes conduz imediatamente nossa atenção em direção ao subtexto permanente dos mesmos: os crimes falam de impunidade. Impunidade é o seu grande tema e, portanto, é a impunidade a porta de entrada para seu deciframento. Poderia ser que, embora o ambiente de cultivo para os assassinados seja o contexto que acabo de descrever, caracterizado pela concentração de poder econômico e político e, portanto, com altos níveis de 
privilégio e proteção para alguns grupos, creio, entretanto, que nos equivocamos quando pensamos na impunidade exclusivamente como um fator causal.

Desejo propor que os feminicídios de Ciudad Juárez podem ser mais bem compreendidos se deixarmos de pensar neles como conseqüência da impunidade e imaginarmos que se comportam como produtores e reprodutores de impunidade. Esta foi minha primeira hipótese e é possível também que tenha sido o primeiro propósito de seus perpetradores na cronologia dos fatos: selar, com a cumplicidade coletivamente compartilhada nas execuções horrendas, um pacto de silêncio capaz de garantir a lealdade inviolável a confrarias mafiosas que operam através da fronteira mais patrulhada do mundo. Dar prova, também, da capacidade de crueldade e poder de morte que negócios de alto perigo requerem. $O$ ritual sacrificial, violento e macabro, une os membros da máfia e torna seu vínculo inviolável. A vítima sacrificial, parte de um território dominado, é forçada a entregar o tributo de seu corpo à coesão e vitalidade do grupo e a mancha de seu sangue define o esotérico pertencimento ao mesmo por parte de seus assassinos. Em outras palavras, mais que uma causa, a impunidade pode ser entendida como um produto, o resultado desses crimes, e os crimes como um modo de produção e reprodução da impunidade: um pacto de sangue nos sangues das vítimas.

Nesse sentido, é possível apontar já aqui uma diferença fundamental entre esse tipo de crime e os crimes de gênero perpetrados na intimidade do espaço doméstico, sobre vítimas que pertencem ao círculo de relações dos abusadores - filhas, afilhadas, sobrinhas, esposas etc. Se ao abrigo do espaço doméstico o homem abusa das mulheres que se encontram sob sua dependência porque pode fazê-lo, quer dizer, porque estas já formam parte do território que controla, o agressor que se apropria do corpo feminino em um espaço aberto, público, o faz porque deve para mostrar que pode. Em um, trata-se de uma constatação de um domínio já existente; em outro, de uma exibição de capacidade de domínio que deve ser reeditada com certa regularidade e pode ser associada a gestos rituais de renovação dos votos de virilidade. O poder está, aqui, condicionado a uma mostra pública dramatizada amiúde em um ato predatório do corpo feminino.

Mas a produção e a manutenção da impunidade mediante o selo de um pacto de silêncio em realidade não se distinguem do que se poderia descrever como a exibição da impunidade. A estratégia clássica do poder soberano para reproduzir-se como tal é divulgar e inclusive espetacularizar o fato de que se encontra para além da lei. 
Podemos entender também dessa forma os crimes de Ciudad Juárez e sugerir que, se por um lado são capazes de selar a aliança no pacto mafioso, por outro lado, também, cumprem com a função de exemplaridade por meio da qual se reforça o poder disciplinador de toda lei.

Isso é assim porque, na capacidade de seqüestrar, torturar e matar reiterada e impunemente, o sujeito autor desses crimes ostenta, para além de qualquer dúvida, a coesão, vitalidade e controle territorial da rede corporativa que comanda. É evidente que a continuidade desse tipo de crime por 11 anos sem que sua recorrência seja perturbada requer fartos recursos humanos e materiais que envolvem: controle de uma rede de associados extensa e leal, acesso a lugares de detenção e tortura, veículos para o transporte da vítima, acesso e influência ou poder de intimidação ou chantagem sobre os membros do governo e da administração pública em todos os seus níveis, inclusive federal. O que é importante notar é que, ao mesmo tempo que essa rede de aliados é acionada por quem comanda os crimes corporativos de Ciudad Juárez, se exibe sua existência, em franca ostentação de um domínio totalitário da localidade.

\section{Os significados}

É precisamente ao cumprir este último papel que os assassinatos passam a comportar-se como um sistema de comunicação. Se escutarmos com atenção as mensagens que ali circulam, poderemos aceder ao rosto do sujeito que por elas fala. Somente depois de compreender o que diz, a quem e para que, poderemos localizar a posição da qual emite seu discurso. É por isso mesmo que devemos insistir em que, cada vez que se invoca o lema da motivação sexual com leviandade antes de analisar minuciosamente o "dito" nesses atos de interlocução, perdemos a oportunidade de seguir o rastro de quem se esconde detrás do texto ensangüentado.

Em outras palavras, os feminicídios são mensagens emanadas de um sujeito autor que só pode ser identificado, localizado, perfilado, mediante uma "escuta" rigorosa desses crimes como atos comunicativos. É em seu discurso que encontramos o sujeito que fala, é em seu discurso que a realidade desse sujeito inscreve-se como identidade e subjetividade e, portanto, torna-se rastreável e reconhecível. Assim mesmo, em seu enunciado, podemos encontrar o rastro de seu interlocutor, sua marca, como um negativo. Isso não é verdade somente para os acting outs violentos que a polícia investiga, mas também para o discurso de 
12 Ver um panorama dessa forma de "escuta" contemporânea do texto em autores como Bakhtin, Lacan, Lévinas e outros em David PATTERSON, 1988.

qualquer sujeito, como o tem explicado uma variedade de filósofos e teóricos literários contemporâneos. ${ }^{12}$

Se o ato violento é entendido como mensagem e os crimes se percebem orquestrados em claro estilo responsorial, encontramos-nos com uma cena onde os atos de violência comportam-se como uma língua capaz de funcionar eficazmente para os entendidos, os avisados, os que a falam, ainda quando não participem diretamente na ação enunciativa. É por isso que, quando um sistema de comunicação com um alfabeto violento instala-se, é muito difícil desinstalá-lo, eliminá-lo. A violência constituída e cristalizada em forma de sistema de comunicação transforma-se em uma linguagem estável e passa a se comportar com o quase-automatismo de qualquer idioma. Perguntar-se, nestes casos, por que se mata em um determinado lugar é semelhante a perguntar-se por que se fala uma determinada língua - o italiano na Itália, o português no Brasil. Um dia, cada uma dessas línguas estabeleceu-se por processos históricos como conquista, colonização, unificação de territórios sob um mesmo Estado nacional ou migrações. Nesse sentido, as razões pelas quais falamos uma língua são arbitrárias e não podem ser explicadas por uma lógica necessária. São, portanto, também históricos os processos pelos quais uma língua é abolida, erradicada de um território. O problema do estupro como linguagem agrava-se ainda mais se considerarmos que existem certas línguas que, em determinadas condições históricas, tendem a converter-se em língua franca e generalizar-se além das fronteiras étnicas ou nacionais que Ihe serviram de nicho originário.

Perguntamos então: Quem fala aqui? Para quem? O que lhe diz? Quando? Qual é a língua do feminicídio? Que significante é o estupro?

Minha resposta é que o autor desse crime é um sujeito que valoriza a ganância e o controle territorial acima de tudo, inclusive acima de sua própria felicidade pessoal. Um sujeito com seu entourage de vassalos que deixa assim absolutamente claro que Ciudad Juárez tem donos, e que esses donos matam mulheres para mostrar que o são. $O$ poder soberano não se afirma se não é capaz de semear o terror.

Dirige-se com isso aos outros homens da comarca, aos tutores ou responsáveis da vítima em seu círculo doméstico e a todos aqueles que são responsáveis por sua proteção como representantes do Estado; fala aos homens das outras fratrias amigas e inimigas para demonstrar os recursos de todo tipo com que conta e a vitalidade de sua rede de sustentação; confirma a seus aliados e sócios nos negócios que a comunhão e a lealdade de grupo continua 
incólume. Diz-lhes que seu controle sobre o território é total, que sua rede de alianças é coesa e confiável, e que seus recursos e contatos são ilimitados.

Pronuncia-se dessa forma quando se consolida uma fratria; quando se planeja um negócio ameaçado pelo perigo do ilícito nessa fronteira patrulhada; quando se abrem as portas para algum novo membro; quando outro grupo mafioso desafia o controle sobre o território; quando há intrusões externas, inspeções, no coto totalitário da localidade.

A língua do feminicídio utiliza o significante corpo feminino para indicar a posição do que pode ser sacrificado em aras de um bem maior, de um bem coletivo, como é a constituição de uma fratria mafiosa. O corpo de mulher é o índice por excelência da posição de quem rende tributo, de vítima cujo sacrifício e consumição poderão mais facilmente ser absorvidos e naturalizados pela comunidade.

É parte desse processo de digestão a acostumada vitimação dupla da já vítima, assim como a vitimação dupla e tripla de sua família, representada na maioria das vezes por uma mãe triste. Um mecanismo de defesa cognitiva quase incontrolável faz com que, para reduzir a dissonância entre a lógica com que esperamos que a vida comportese e a maneira na qual ela se comporta na realidade, odiemos a quem encarna essa inversão, essa infração à gramática da sociabilidade. Diante da ausência definitiva de um agressor, alguém tem que ser responsabilizado pelo infortúnio coletivo assim causado. Assim como é comum que o condenado recorde de sua vítima com um grande rancor por associá-la ao desenlace de seu destino e à perda de sua liberdade, da mesma forma a comunidade mergulha mais e mais em uma espiral misógina que, na falta de um apoio mais adequado para desfazer-se de seu mal-estar, permite-Ihe depositar na própria vítima a culpa pela crueldade com que foi tratada. Facilmente optamos por reduzir nosso sofrimento diante da injustiça intolerável testemunhada, alegando que "deve haver uma razão". Assim, as mulheres assassinadas de Ciudad Juárez transformam-se rapidamente em prostitutas, mentirosas, festeiras, viciadas em drogas e em tudo aquilo que nos possa liberar da responsabilidade e da amargura que nos inocula ao deparar-nos com sua sorte injusta.

Na língua do feminicídio, corpo feminino também significa território, e sua etimologia é tão arcaica quanto suas transformações são recentes. Tem sido constitutivo da linguagem das guerras, tribais ou modernas, que o corpo da mulher anexe-se como parte do país conquistado. A sexualidade investida sobre o mesmo expressa 0 ato domesticador, apropriador, quando insemina o território- 
corpo da mulher. Por isso, a marca do controle territorial dos senhores de Ciudad Juárez pode ser inscrita no corpo de suas mulheres como parte ou extensão do domínio afirmado como próprio.

O estupro coletivo é, como nos pactos de sangue, a mistura de substâncias corporais de todos os que dele participam; o ato de compartilhar a intimidade em seu aspecto mais feroz, de expor o que se guarda com mais zelo. Como o corte voluntário do qual surge o sangue, o estupro é uma publicação da fantasia, da transgressão de um limite, um gesto radicalmente comprometedor.

O estupro, a dominação sexual, tem também como característica conjugar o controle não somente físico, mas também moral da vítima e seus associados. A redução moral é um requisito para que a dominação se consuma e a sexualidade, no mundo que conhecemos, está impregnada de moralidade.

O que é, então, um feminicídio, no sentido que Ciudad Juárez Ihe confere a essa palavra? É o assassinato de uma mulher genérica, de um tipo de mulher, só por ser mulher e pertencer a esse tipo, da mesma forma que o genocídio é uma agressão genérica e letal a todos aqueles que pertencem ao mesmo grupo étnico, racial, lingüístico, religioso ou ideológico. Ambos os crimes dirigem-se a uma categoria, não a um sujeito específico. Precisamente, esse sujeito é despersonalizado como sujeito porque se faz predominar nele a categoria à qual pertence sobre suas características individuais biográficas ou de personalidade.

Existe, porém, me parece, uma diferença entre esses dois tipos de crime que deveria ser mais bem examinada e discutida. Se no genocídio a construção retórica do ódio ao outro conduz a ação de sua eliminação, no feminicídio a misoginia por detrás do ato é um sentimento mais próximo ao dos caçadores por seu troféu: parece-se ao desprezo por sua vida ou à convicção de que o único valor dessa vida radica-se em sua disponibilidade para a apropriação.

Os crimes, assim, pareceriam falar de um verdadeiro Direito de Pernada bestial de um Senhor feudal e pósmoderno com seu grupo de acólitos, como expressão por excelência de seu domínio absolutista sobre um território, onde o direito sobre o corpo da mulher é uma extensão do direito do senhor sobre sua gleba. Entretanto, na mais que terrível ordem contemporânea pós-moderna, neoliberal, pós-estatal, pós-democrática, o Senhor tornou-se capaz de controlar de forma quase irrestrita seu território como conseqüência da acumulação descontrolada característica da região de expansão fronteiriça, exacerbada pela globalização da economia, e das regras soltas do mercado neoliberal em vigência. Sua única força 
reguladora radica-se na cobiça e na potência de rapina de seus competidores: os outros Senhores do lugar. Microfascismos regionais e seu controle totalitário da província acompanham a decadência de ordem nacional deste lado da Grande Fronteira e urgem, mais do que nunca, a aplicação de formas de legalidade e controle de cunho internacionalista.

A misteriosa morte das mulheres de Ciudad Juárez pode ser a pista definitiva de que a descentralização, em um contexto de desestatização e de neoliberalismo, não pode senão instalar um totalitarismo de província, em uma conjunção regressiva entre pós-modernidade e feudalismo, em que o corpo feminino volta a ser anexado ao domínio territorial.

\section{As condições de possibilidade}

A extrema assimetria devido à extração desregulada de ganâncias por parte de um grupo é uma condição crucial para que se estabeleça um contexto de impunidade. Quando a desigualdade de poderes é tão extrema como em um regime irrestrito neoliberal, não há possibilidade real de separar negócios lícitos de negócios ilícitos, já que a desigualdade torna-se tão acentuada que permite o controle territorial absoluto em nível subestatal por parte de alguns grupos e suas redes de sustentação e aliança. Essas redes instalam, então, um verdadeiro totalitarismo de província e passam a demarcar e expressar sem ambigüidades o regime de controle vigente na região. Os crimes de mulheres sem ambigüidades de Ciudad Juárez parece-me uma forma de significar esse tipo de domínio territorial.

Uma característica forte dos regimes totalitários é o fechamento, a representação do espaço totalitário como um universo sem lado de fora, encapsulado e autosuficiente, em que uma estratégia de barricada por parte das elites impede os habitantes de aceder a uma percepção diferente, exterior, alternativa, da realidade. Uma retórica nacionalista que se afirma em uma construção primordialista da unidade nacional - como é o caso da "mexicanidade" no México, da "civilização tropical" no Brasil ou do "ser nacional" na Argentina - beneficia os que detêm o controle territorial e o monopólio da voz coletiva.

Essas metafísicas da nação baseadas em um essencialismo anti-histórico, por mais populares e reivindicativas que possam apresentar-se, trabalham com os mesmos procedimentos lógicos que ampararam o nazismo. Esse mesmo tipo de ideologia nacional pode ser também encontrado quando uma elite regional consolida 
seu domínio sobre o espaço e legitima seus privilégios em uma ideologia primordialista da região, quer dizer, trabalhando sua identificação com um grupo étnico ou com uma herança de civilização. Consignas nativistas poderosas pressionam para a formação de um sentimento de lealdade aos emblemas da unidade territorial com os quais a elite por outro lado, desenha sua heráldica. Cultura popular significa, em um meio totalitário, cultura apropriada; povo são os habitantes do território controlado; e autoridades são os donos do discurso, da cultura tradicional, da riqueza produzida pelo povo, e do território totalizado.

Como no totalitarismo de uma nação, uma das estratégias principais do totalitarismo de região é a de avisar/ prevenir a coletividade contra qualquer discurso que possa ser tachado de não-autóctone, não emanado e selado pelo compromisso da lealdade interior. "Estrangeiro" e "estranho na comarca" são transformados em categorias de acusação e confisca-se a possibilidade de falar "de fora". Portanto, a retórica é a de um patrimônio cultural que há de ser defendido acima de tudo e a de uma lealdade territorial que predomina e exclui outras lealdades - como, por exemplo, a do cumprimento da lei, a da luta pela expansão dos direitos e a da demanda de ativismo e arbitragem internacional para a proteção dos direitos humanos. É por isso que, se o "lado de dentro" e o estado de sítio midiático são a estratégia inequívoca dos líderes totalitários, o "lado de fora" é sempre o ponto de apoio para a ação no campo dos direitos humanos.

Em um ambiente totalitário, o valor mais martelado é o nós. O conceito de nós torna-se defensivo, entrincheirado, patriótico, e quem o infrinja é acusado de traição. Nesse tipo de patriotismo, a primeira vítima são os outros interiores da nação, da região, da localidade sempre as mulheres, os negros, os povos originários, os dissidentes. Esses outros interiores são coagidos para que sacrifiquem, calem e posterguem sua queixa e o argumento de sua diferença em nome da unidade sacralizada e essencializada da coletividade.

É brandindo esse conjunto de representações tipicamente totalitárias - de um totalitarismo de província que os meio de comunicação juarenses desqualificam um a um os observadores externos. O discurso dos meios, quando se "escuta" o subtexto da notícia, quando se lê nas entrelinhas, é: é melhor um assassino próprio, por mais cruel que seja, do que um justiceiro alheio, ainda que tenha razão. Essa conhecida estratégia propagandística elementar constrói, todos os dias, diante de qualquer ameaça do olhar exterior, a muralha totalitária de Ciudad Juárez, e tem 
${ }^{13}$ Alexandre KOYRÉ, 1945.

${ }^{14}$ ARENDT, 1998 [1949], p. 425427. contribuído, ao longo destes 11 anos, para escamotear a verdade do povo e para neutralizar as forças da lei que resistem a uma articulação protética com os poderes locais. Impossível não lembrar de Ciudad Juárez quando lemos Hannah Arendt:

Os movimentos totalitários têm sido chamados de "sociedades secretas à luz do dia". ${ }^{13}$ Realmente, [...] a estrutura dos movimentos [...] lembra-nos em primeiro lugar certas características dessas sociedades. As sociedades secretas formam também hierarquias de acordo com o grau de "iniciação", regulam a vida dos seus membros segundo um pressuposto secreto e fictício que faz com que cada coisa pareça ser outra coisa diferente; adotam uma estratégia de mentiras coerentes para iludir as massas de fora, não iniciadas; exigem obediência irrestrita dos seus membros, que são mantidos coesos pela fidelidade a um líder frequentemente desconhecido e sempre misterioso, rodeado, ou supostamente rodeado, por um pequeno círculo de iniciados; e estes, por sua vez, são rodeados por semi-iniciados que constituem uma espécie de "amortecedor" contra o mundo profano e hostil. Os movimentos totalitários têm ainda em comum com as sociedades secretas a divisão dicotômica do mundo entre "irmãos jurados de sangue" e uma massa indistinta e inarticulada de inimigos jurados [...] baseada na absoluta hostilidade contra o mundo que os rodeia. [...] Talvez a mais clara semelhança entre as sociedades secretas e os movimentos totalitários esteja na importância do ritual. [...] [entretanto], essa idolatria não prova a existência de tendências pseudo-religiosas ou heréticas [...], são simples truques organizacionais, muito praticados nas sociedades secretas, que também forçavam os seus membros a guardar segredo por medo e respeito a símbolos assustadores. As pessoas unem-se mais firmemente através da experiência partilhada de um ritual secreto do que pela simples admissão ao conhecimento do segredo. ${ }^{14}$

Porém, que Estado é esse?; que liderança é essa que produz o efeito de um totalitarismo regional? É um segundo Estado que necessita de um nome. Um nome que sirva de base para a categoria jurídica capaz de enquadrar na lei seus donos e a rede de cumplicidade que controlam. Os feminicídios de Ciudad Juárez não são crimes comuns de gênero e sim crimes corporativos e, mais especificamente, são crimes de segundo Estado, de Estado paralelo. Assemelham-se mais, por sua fenomenologia, aos rituais que cimentam a unidade de sociedades secretas e regimes totalitários. Compartilham uma característica idiossincrática com os abusos do poder político: apresentam-se como crimes sem sujeito personalizado realizados sobre uma vítima também não personalizada: um poder secreto abduz 
um tipo de mulher, victimizando-a para reafirmar e revitalizar sua capacidade de controle. Portanto, são mais próximos a crimes de Estado, crimes de lesa humanidade, onde o Estado paralelo que os produz não pode ser enquadrado porque carecemos de categorias e procedimentos jurídicos eficientes para enfrentá-lo.

É por isso que seria necessário criar novas categorias jurídicas para enquadrá-los e torná-los juridicamente inteligíveis, classificáveis: não são crimes comuns, ou seja, não são crimes de gênero de motivação sexual ou de falta de entendimento no espaço doméstico, como afirmam frivolamente agentes da lei, autoridades e ativistas. São crimes que poderiam ser chamados de segundo Estado ou crimes de corporação, nos quais a dimensão expressiva da violência prevalece. Entendo aqui "corporação" como o grupo ou rede que administra os recursos, direitos e deveres próprios de um Estado paralelo, estabelecido firmemente na região e com tentáculos nas cabeceiras do país.

Se invertêssemos os termos por um momento e disséssemos que o telos ou finalidade do capital e dos "mandamentos da capitalização" não é o processo de acumulação, porque isso significaria cair em uma tautologia (a finalidade da acumulação é a acumulação; a finalidade da concentração é a concentração) e, portanto, estaríamos descrevendo o ciclo fechado de um fim em si mesmo; se em vez disso disséssemos que a finalidade do capital é a produção da diferença mediante a reprodução e ampliação progressiva da hierarquia até o ponto do extermínio de alguns como expressão incontestável de seu êxito, concluiríamos que somente a morte de alguns é capaz de alegorizar idoneamente e de forma auto-evidente o lugar e a posição de todos os dominados, do povo dominado, da classe dominada. É na exclusão e seu significante por excelência, a capacidade de supressão do outro, que o capital se consagra. E o que poderia ser mais emblemático do lugar de submetimento que o corpo da mulher mestiça, da mulher pobre, da filha e da irmã dos outros que são pobres e mestiços? Onde se poderia significar melhor a outridade produzida justamente para ser vencida? Que troféu emblematizaria melhor a sinecura de ótimos negócios para além de qualquer regra ou restrição? Essa duplamente outra mulher emerge assim na cena como o lugar da produção e da significação da última forma de controle territorial totalitário - de corpos e terrenos, de corpos como parte de terrenos - pelo ato de sua humilhação e supressão.

Encontramo-nos, assim, diante do sem-limite de ambas as economias - simbólica e material. A predação e 
rapina do ambiente e da mão-de-obra dão-se as mãos com o estupro sistemático e corporativo. Não nos esqueçamos que rapina, em português, comparte sua raiz com rape, estupro em inglês.

Se isso é assim, não somente podemos afirmar que uma compreensão do contexto econômico em grande escala ajuda-nos a iluminar os acontecimentos de Ciudad Juárez, mas também que as humildes mortas de Juárez, a partir da pequena escala de sua situação e localidade, despertam-nos e conduzem-nos a uma releitura mais lúcida das transformações que atravessam o mundo em nossos dias, enquanto este se torna, a cada instante, mais inóspito e aterrador.

\section{Referências bibliográficas}

AMIR, Menacher. Patterns in Forcible Rape. Chicago and Londres: The University of Chicago Press, 1971.

ARENDT, Hannah. Origens do totalitarismo. São Paulo: Companhia das Letras, 1998 [1949]. ATENCIO, Graciela. "El circuito de la muerte". La Jornada, n. 61, sept. 2003. Triple Jornada - suplemento feminista del diario La Jornada.

DERRIDA, Jacques. Marges de la philosophie. Paris: Minuit, 1972.

FOUCAULT, Michel. "Aula de 17 de março de 1976". In: Em defesa da sociedade: curso no Collège de France (1975-1976). São Paulo: Martins Fontes, 1999.

GONZÁLEZ RODRÍGUEZ, Sergio. Huesos en el desierto. Barcelona: Anagrama, 2002.

KOYRÉ, Alexandre. "The Political Function of the Modern Lie." Contemporary Jewish Record, jun. 1945

PATTERSON, David. Literature and Spirit. Essays on Bakhtin and his Contemporaries. Lexington: The University Press of Kentucky, 1988.

RADFORD, Jill, and RUSSELL, Diana E. H. Femicide: The Politics of Woman Killing. New York: Twayne Publishers, 1992.

SEGATO, Rita Laura: Las estructuras elementales de la violencia: ensayos sobre género entre la Antropología, el Psicoanálisis y los Derechos Humanos. Buenos Aires: Universidad Nacional de Quilmes/Prometeo 3010, 2003.

WASHINGTON VALDEZ, Diana. Cosecha de mujeres. México, DF: Editorial Océano, 2005.

[Recebido em março de 2005 e aceito para publicação em maio de 2005] 


\begin{abstract}
Territory, Sovereignty and Second State Crimes: the Writing on the Bodies of the Assassinated Women of Ciudad Juarez

Abstract: The essay examines the case of the feminicides that rendered at least three hundred women murdered during the last twelve years in Ciudad Juárez, Chihuahua, at the Northern Mexican border. In all these years, the authorities presented only a few suspects, without ever getting to convince public opinion of their culpability. Impunity and protection for the murderers are evident to local public opinion and to international observers. I argue that what is written on the body of the brutally murdered women is the signature of a local and regional power counting also with national connections. These acts of apparently irrational violence state beyond doubt the discretionary power of their perpetrators and the control they exert over the people and resources of their territory, thus sealing and reinforcing a pact of fraternity.

Key Words: Expressive violence, gender violence, mafias, masculinity, territoriality.
\end{abstract}

Tradução de Anand Dacier 